\title{
Analyse van prestaties van buitenlandse artsen tijdens het co-assistentschap huisartsgeneeskunde
}

\author{
E.A. van Hell, J. Greidanus, F. Beltman, J. Cohen-Schotanus
}

\begin{abstract}
Samenvatting
Inleiding: CIBA-studenten zijn buitenlandse artsen die een deel van de opleiding tot basisarts volgen aan een medische faculteit. Begeleiders van co-assistenten geven aan dat CIBAstudenten problemen ondervinden op het gebied van taal en communicatie. Echter, een empirische onderbouwing van deze klachten ontbreekt. In dit onderzoek wordt geanalyseerd of CIBA-studenten verschillend presteren ten opzichte van reguliere studenten en op welke specifieke punten eventuele verschillen het duidelijkst zijn. Zo zal getracht worden de geluiden uit de praktijk te objectiveren.
\end{abstract}

Methode: Van 24 CIBA-studenten en 24 reguliere studenten van het Universitair Medisch Centrum Groningen zijn de studieresultaten van het zesdejaars co-assistentschap huisartsgeneeskunde geanalyseerd. De studieresultaten zijn gebaseerd op vijf beoordelingsformulieren waarvan de items betrekking hebben op verschillende facetten van een huisartsenconsult. Per beoordelingsformulier is, voor zowel CIBA- als reguliere studenten, de gemiddelde score op de afzonderlijke items berekend. Analyse volgt met behulp van de Wilcoxon signed-ranks test.

Resultaten: CIBA-studenten scoren op meer items lager dan reguliere studenten. Deze trend is significant voor twee formulieren (eindbeoordeling stage; examenpatiënt I). Het lager scoren is het duidelijkst voor de items 'bespreking met patiënt', 'arts-patiëntrelatie kunnen opbouwen' en 'beleidsplan/vaardigheden'.

Conclusie: CIBA-studenten presteren iets minder goed tijdens de stage huisartsgeneeskunde dan reguliere studenten. De items waarvoor de verschillen het duidelijkst zijn, lijken betrekking te hebben op de communicatieve en sociale omgang tussen de arts en de patiënt. Toch moet vanwege de kleine onderzoeksgroep en wellicht andere van invloed zijnde variabelen die niet meegenomen zijn in dit onderzoek, voorzichtig met deze conclusie omgegaan worden. (Hell EA van, Greidanus J, Beltman F, Cohen-Schotanus J. Analyse van prestaties van buitenlandse artsen tijdens het co-assistentschap huisartsgeneeskunde. Tijdschrift voor Medisch Onderwijs 2006;25(1):22-28.)

\section{Inleiding}

Buitenlandse artsen van wie het artsdiploma niet gelijkgesteld is aan het $\mathrm{Ne}$ derlandse artsdiploma moeten, om zich als erkend arts in Nederland te kunnen vestigen, een deel van de opleiding tot basisarts volgen aan één van de medische faculteiten. Om geplaatst te worden bij de opleiding geneeskunde kunnen deze artsen zich aanmelden bij de Commissie Instroom Buitenlandse Artsen (CIBA). In de Nederlandse literatuur wordt veelal aangegeven dat de Nederlandse taal een obstakel is voor veel buitenlandse studenten bij het doorlopen van hun opleiding. ${ }^{1-}$ 3 Buitenlandse studenten ondervinden problemen met het discussiëren, schrijven en lezen van anderstalig studiemateriaal. Ook het veelvuldige gebruik van spreekwoorden en gezegden in de Nederlandse taal leidt regelmatig tot misverstanden en onbegrip. 
Begeleiders van coassistenten geven regelmatig aan dat de CIBA-studenten problemen ondervinden op het gebied van taal en communicatie. Echter, een empirische onderbouwing van deze klachten ontbreekt. Deze signaleringen tezamen met de problemen die in de literatuur genoemd worden, hebben geleid tot de volgende onderzoeksvraag: Zijn studieproblemen van CIBA-studenten terug te vinden in de formele beoordelingen? Door het beantwoorden van deze vraag zal getracht worden geluiden vanuit de praktijk enigszins te objectiveren. Om te achterhalen of problemen terug te vinden zijn in studieresultaten, zal onderzocht worden hoe CIBA-studenten presteren en of deze prestaties verschillen van die van reguliere studenten. Vervolgens wordt geanalyseerd op welke specifieke gebieden eventuele verschillen het duidelijkst zijn.

\section{Methode}

\section{Onderzoeksgroep}

Om inzicht te krijgen in de prestaties van CIBA-studenten en reguliere studenten is onderzoek gedaan onder studenten van het Universitair Medisch Centrum Groningen (UMCG). Jaarlijks worden zo'n tien tot vijftien CIBA-studenten toegelaten tot het derde jaar van de opleiding geneeskunde. Voor dit onderzoek zijn de studieresultaten geanalyseerd van alle CIBA-studenten $(n=24)$ die het zesdejaars coassistentschap huisartsgeneeskunde vanaf juni 2002 gevolgd hebben en beoordeeld werden met behulp van beoordelingsformulieren. Vergelijking heeft plaatsgevonden met een groep niet-CIBA-studenten $(n=24)$ die naar rato aselect getrokken zijn uit vertegenwoordigde stageperiodes. Deze studenten worden hier 'reguliere studenten' genoemd. Er is gekozen voor de vierweekse stage huisartsgeneeskunde omdat het onderwijs- en examenprogramma van deze stage goed gestructureerd is. De studenten worden regelmatig geobserveerd en ontvangen feedback. Ook het examen wordt geobserveerd. De huisartsen bij wie de studenten stage lopen (begeleidende huisartsen) en de huisartsen die de examens afnemen (huisarts-examinatoren) zijn getraind voor hun rol.

\section{Materiaal}

De beoordeling van de studenten vindt plaats door middel van vijf beoordelingsformulieren die gedeeltelijk dezelfde items bevatten (tabel 1). De items hebben betrekking op verschillende facetten van een huisartsconsult zoals het uitvoeren van een anamnese en lichamelijk onderzoek, omgang met de patiënt en professioneel gedrag. De begeleider vult de beoordelingsformulieren tijdens en na de stage in (tabel 2) en geeft een stagecijfer. De vier weken stage worden afgesloten met twee examenpatiënten die beoordeeld worden door de examinator. Hieruit volgt een examencijfer. De stage- en examenbeoordelaars zijn altijd twee verschillende huisartsen. Het gemiddelde van het stagecijfer en het examencijfer is het eindcijfer voor de stage huisartsgeneeskunde.

\section{Procedure en analyse}

De items worden gescoord op ordinaal niveau met drie antwoordmogelijkheden (onvoldoende, voldoende, goed). Om gemiddelde scores per item te kunnen berekenen, worden de beoordelingen omgeschaald naar een dichotome schaal. Omdat slechts 19 van de 2880 (48 studenten $\times 60$ items) keer een onvoldoende gegeven wordt, krijgen de beoordelingen 'onvoldoende' en 'voldoende' beide de waarde 0 en de beoordeling 'goed' de waarde 1.

Gezien de beperkte omvang van de onderzoeksgroep is gekozen voor een nonparametrische analyse. Hiervoor is per beoordelingsformulier, voor zowel CIBA- als 
Tabel 1 Beschrijvende gegevens en de Wilcoxon signed-ranks test voor de items uit de beoordelingsformulieren.*

\begin{tabular}{|c|c|c|c|c|c|}
\hline \multirow[t]{2}{*}{ Items } & \multicolumn{2}{|c|}{ Gemiddelde } & \multirow{2}{*}{ Verschil } & \multirow[t]{2}{*}{ Z } & \multirow[t]{2}{*}{ p-tweezijdig } \\
\hline & CIBA & Regulier & & & \\
\hline Voortgangsevaluatie & & & & -.980 & .327 \\
\hline Probleemherkenning en omschrijving & .46 & .59 & -.13 & & \\
\hline Anamnese & .46 & .70 & -.24 & & \\
\hline Lichamelijk onderzoek & .63 & .48 & .15 & & \\
\hline Probleemanalyse (bij nabespreking) & .52 & .30 & .22 & & \\
\hline Bespreking met patiënt & .57 & .73 & -.16 & & \\
\hline Beleidsplan/vaardigheden & .41 & .57 & -.16 & & \\
\hline Aanvullend onderzoek & .45 & .45 & .00 & & \\
\hline Verwijzen en consulteren & .47 & .59 & -.12 & & \\
\hline Arts-patiëntrelatie kunnen opbouwen & .63 & .64 & -.01 & & \\
\hline Professioneel gedrag & & & & -.260 & .795 \\
\hline Omgaan met beschikbare tijd & .70 & .75 & -.05 & & \\
\hline Opstelling in het werk/onderwijs & .91 & .71 & .20 & & \\
\hline Procedurele zorgvuldigheid & .83 & .81 & .02 & & \\
\hline Zelfstandigheid & .78 & .67 & .11 & & \\
\hline Zelfvertrouwen & .74 & .57 & .17 & & \\
\hline Houding & .83 & .86 & -.03 & & \\
\hline Samenwerking & .78 & .90 & -.12 & & \\
\hline Collegiaal gedrag & .91 & .95 & -.04 & & \\
\hline Omgang met patiënten & .96 & .95 & .00 & & \\
\hline Zorg voor patiënten & .74 & .85 & -.11 & & \\
\hline Omgang met ander personeel dan artsen & .83 & .90 & -.07 & & \\
\hline Taalvaardigheid en uitdrukkingsvermogen & .63 & .88 & -.25 & & \\
\hline Omgaan met kritiek van anderen & .96 & .95 & .01 & & \\
\hline Geven van kritiek/feedback op anderen & .77 & .67 & .10 & & \\
\hline Vermogen tot zelfanalyse & .83 & .86 & -.03 & & \\
\hline Verschijning/verzorging & .96 & .85 & .11 & & \\
\hline Op tijd verschijnen & .91 & 1.00 & -.09 & & \\
\hline Eindbeoordeling stage & & & & -2.840 & .005 \\
\hline Probleemherkenning en omschrijving & .77 & .75 & .02 & & \\
\hline Anamnese & .82 & .79 & .03 & & \\
\hline Lichamelijk onderzoek & .77 & .75 & .02 & & \\
\hline Probleemanalyse (bij nabespreking) & .48 & .72 & -.24 & & \\
\hline Bespreking met patiënt & .59 & .74 & -.15 & & \\
\hline Beleidsplan/vaardigheden & .55 & .74 & -.19 & & \\
\hline Aanvullend onderzoek & .64 & .64 & .00 & & \\
\hline Verwijzen en consulteren & .57 & .63 & -.06 & & \\
\hline Vastlegging en registratie & .62 & .75 & -.13 & & \\
\hline Begeleiding & .67 & .75 & -.08 & & \\
\hline Preventie & .21 & .57 & -.36 & & \\
\hline Arts-patiëntrelatie kunnen opbouwen & .70 & .88 & -.18 & & \\
\hline Persoonlijke eigenschappen & .64 & .74 & -.10 & & \\
\hline Werk en privéleven kunnen combineren & .53 & .85 & -.32 & & \\
\hline
\end{tabular}


Vervolg tabel 1

\begin{tabular}{|c|c|c|c|c|c|}
\hline \multirow[t]{2}{*}{ Items } & \multicolumn{2}{|c|}{ Gemiddelde } & \multirow{2}{*}{ Verschil } & \multirow[t]{2}{*}{$\mathbf{Z}$} & \multirow[t]{2}{*}{ p-tweezijdig } \\
\hline & CIBA & Regulier & & & \\
\hline Kleine chirurgische ingrepen uitvoeren & .54 & .80 & -.26 & & \\
\hline Inzet tijdens co-schap & 1.00 & .96 & .04 & & \\
\hline Examenpatiënt I & & & & -2.075 & .038 \\
\hline Probleemherkenning en omschrijving & .65 & .74 & -.09 & & \\
\hline Anamnese & .65 & .74 & -.09 & & \\
\hline Lichamelijk onderzoek & .61 & .78 & -.17 & & \\
\hline Probleemanalyse (bij nabespreking) & .41 & .58 & -.17 & & \\
\hline Bespreking met patiënt & .61 & .71 & -.10 & & \\
\hline Beleidsplan/vaardigheden & .61 & .63 & -.02 & & \\
\hline Aanvullend onderzoek & .50 & .69 & -.19 & & \\
\hline Verwijzen en consulteren & .75 & .63 & .12 & & \\
\hline Arts-patiëntrelatie kunnen opbouwen & .61 & .83 & -.22 & & \\
\hline Examenpatiënt II & & & & -1.955 & 0.51 \\
\hline Probleemherkenning en omschrijving & .61 & .83 & -.22 & & \\
\hline Anamnese & .71 & .71 & .00 & & \\
\hline Lichamelijk onderzoek & .71 & .67 & .04 & & \\
\hline Probleemanalyse (bij nabespreking) & .62 & .70 & -.08 & & \\
\hline Bespreking met patiënt & .57 & .88 & -.31 & & \\
\hline Beleidsplan/vaardigheden & .62 & .71 & -.09 & & \\
\hline Aanvullend onderzoek & .80 & .79 & .01 & & \\
\hline Verwijzen en consulteren & .50 & 1.00 & -.50 & & \\
\hline Arts-patiëntrelatie kunnen opbouwen & .59 & .90 & -.31 & & \\
\hline
\end{tabular}

* De beschrijvende gegevens zijn afgerond op twee decimalen; de variabelen zijn omgezet naar dichotoom niveau (0 of 1); cursief afgedrukte items worden slechts éénmaal beoordeeld.

Tabel 2 Overzicht beoordelingsformulieren.

\begin{tabular}{lcll}
\hline Beoordelingsformulier & Aantal items & Beoordelaar & Moment \\
\hline Voortgangsevaluatie & 9 & Begeleider & Na 2 weken stage \\
Professioneel gedrag & 17 & Begeleider & Na 4 weken stage \\
Eindbeoordeling stage & 16 & Begeleider & Na 4 weken stage \\
Examenpatiënt I & 9 & Examinator & Na stage en examen \\
Examenpatiënt II & 9 & Examinator & Na stage en examen \\
\hline
\end{tabular}

reguliere studenten, de gemiddelde score op de afzonderlijke items berekend. Met behulp van de Wilcoxon signed-ranks test is onderzocht of hierin een trend aangetoond kan worden.

Verder is per item het verschil tussen de gemiddelde score van de CIBA-studenten en de gemiddelde score van de reguliere studenten berekend. Omdat voor het berekenen van de verschillen de gemiddelde score van de reguliere studenten afgetrokken wordt van die van de CIBA-studenten, wijst een negatief verschil op hoger scorende reguliere studenten en een positief verschil op hoger scorende CIBA-studenten (tabel 1). Na het berekenen van de ver- 
schillen is geanalyseerd welke items bij alle beoordelingsformulieren waarin het item voorkomt een verschil in dezelfde richting laten zien. Items die de ene keer een positief en de andere keer een negatief verschil laten zien, worden dus niet beschouwd als indicatie voor een duidelijk verschil tussen de onderzoeksgroepen. De items die slechts in één beoordelingsformulier aan de orde komen, worden buiten beschouwing gelaten, omdat hier sprake kan zijn van toeval. Dit geldt voor alle items in het beoordelingsformulier 'professioneel gedrag' en zeven items in het beoordelingsformulier 'eindbeoordeling stage' (tabel 1).

Om onderzoeksresultaten beter te kunnen interpreteren worden tot slot de gemiddelde stage-, examen- en eindcijfers van CIBA-studenten en reguliere studenten berekend.

\section{Resultaten}

Bij alle vijf beoordelingsformulieren zijn er meer items waarop de CIBA-studenten gemiddeld lager scoren. Voor de beoordelingsformulieren 'eindbeoordeling stage' $(\mathrm{Z}=-2.84 ; \mathrm{p}=0.005)$, 'examenpatiënt I' $(\mathrm{Z}=$ $-2.08 ; \mathrm{p}=0.038)$ is deze trend tevens significant (tabel 1).

Van de 60 afzonderlijke items worden de CIBA-studenten op 39 items lager beoordeeld dan de reguliere studenten, 3 keer gelijk en 18 keer hoger. De 39 items waarop de CIBA-studenten lager beoordeeld worden dan de reguliere studenten laten een absoluut verschil zien van gemiddeld 0.16. Voor de 18 items waarop CIBA-studenten hoger scoren is dit gemiddelde de helft hiervan (0.08). De items 'arts-patiëntrelatie kunnen opbouwen', 'bespreking met patiënt' en 'beleidsplan/vaardigheden' laten op alle beoordelingsformulieren waarin ze voorkomen een negatief verschil zien.

Gemiddeld scoren de studenten op de stage een 7.97 (CIBA 7.84 en regulier 8.09) en op het examen een 7.53 (CIBA 7.33 en regulier 7.73). Het gemiddelde eindcijfer voor de stage huisartsgeneeskunde is 7.79 (CIBA 7.67 en regulier 7.90).

\section{Discussie en conclusie}

Dit onderzoek had als doel de gevoelens van begeleiders, dat CIBA-studenten tijdens de coassistentschappen problemen ondervinden op het gebied van taal en communicatie, empirisch te onderbouwen. Kijkend naar de onderzoeksresultaten kan gesteld worden dat CIBA-studenten vaker lager scoren dan de reguliere studenten. Wanneer CIBA-studenten gemiddeld lager scoren is het absolute verschil tussen beide onderzoeksgroepen ook nog eens twee keer zo groot als wanneer zij gemiddeld hoger scoren dan de reguliere studenten. Wanneer het onderzoek gericht wordt op de afzonderlijke items dan zijn er drie items die bij alle vier beoordelingsformulieren waarin ze voorkomen steeds een verschil in dezelfde richting laten zien. Deze items (arts-patiëntrelatie kunnen opbouwen; bespreking met patiënt; beleidsplan/vaardigheden) lijken voor een groot deel betrekking te hebben op de communicatieve en sociale omgang tussen de arts en de patiënt. De onderzoeksresultaten ondersteunen slechts gedeeltelijk de geluiden uit de praktijk. CIBA-studenten scoren lager in de praktijk en alhoewel de drie items wijzen op moeilijkheden op het gebied van communicatie en sociale omgang kan dit niet met zekerheid gezegd worden.

Bij deze conclusie moeten enkele kanttekeningen gemaakt worden. Het onderzoek is uitgevoerd onder een klein aantal studenten. Dit brengt het nadeel met zich mee dat het uitvoeren van een t-toets of multivariate analyse om verschillen tussen CIBA- en reguliere studenten te vinden en te verklaren, resulteerde in een te laag onderscheidingsvermogen (power). 
Een gedegen middel om verschillen op itemniveau vast te stellen ontbreekt dus. Op het moment dat dit onderzoek is uitgevoerd, waren er echter niet meer CIBAstudenten van wie de beoordelingsformulieren van de stage huisartsgeneeskunde beschikbaar waren. De steekproefomvang kon dus niet vergroot worden. Verder zijn de items gescoord op ordinaal niveau met 'onvoldoende', 'voldoende' en 'goed' als antwoordmogelijkheden. Omdat slechts zelden een onvoldoende gegeven werd, is de spreiding van de itemscores klein, waardoor de scores weinig onderscheid maken tussen studenten. Om deze redenen werd dan ook geen gebruik gemaakt van de Student's t-toets of een multivariate analyse, maar werd de Wilcoxon signed-ranks test uitgevoerd.

Bij het berekenen van de verschillen voor de gemiddelde scores per item kunnen waarden tussen de -1 (gemiddelde score CIBA-studenten is 0 en gemiddelde score reguliere studenten is 1 ) en 1 (gemiddelde score CIBA-studenten is 1 en gemiddelde score reguliere studenten is 0 ) gevonden worden. Ondanks deze kleine range worden toch relatief grote verschillen ( -0.5 tot 0.22 ) gevonden, hetgeen opmerkelijk is en duidt op verschillen die wellicht de moeite waard zijn. Ook is opmerkelijk dat voor items waarop CIBA-studenten lager scoren dan reguliere studenten het gemiddelde verschil absoluut gezien veel groter is dan voor de items waarvoor zij hoger scoren. Ook hier ontbreekt, door eerder genoemde redenen, een gedegen statistische methode om significante verschillen aan te kunnen tonen. Ondanks deze relatief grote verschillen is geen van de studenten gezakt voor de stage huisartsgeneeskunde. Beide groepen halen gemiddeld zelfs vrij hoge eindcijfers voor het studieonderdeel en de overall prestatie van de CIBA-studenten lijkt dus voldoende. Dit suggereert dat CIBA-studenten, ondanks het lager scoren op bepaalde items, goed in staat zijn een huisartsconsult uit te voeren en dit stelt de gevonden verschillen in een ander perspectief.

Naast deze methodologische kanttekeningen moeten nog enkele meer inhoudelijke opmerkingen geplaatst worden. In dit onderzoek zijn enkele variabelen niet meegenomen die wellicht wel hun invloed uitoefenen op de prestaties van de (CIBA)studenten. Zo kan onvoldoende medische kennis leiden tot moeilijkheden op het gebied van taal en communicatie en op die manier fungeren als interveniërende variabele. Deze kennis is echter geen onderdeel van het formele huisartsgeneeskunde-examen. Ook het land van herkomst kan van invloed zijn op de studieresultaten van de CIBA-studenten. Wellicht hebben studenten uit meer westerse landen minder moeite met de Nederlandse artspatiëntrelatie dan studenten die als vluchteling uit het middenoosten komen. Het land van herkomst is echter onbekend bij dit onderzoek.

Dat de gemiddelde eindcijfers relatief hoog zijn, zou kunnen komen doordat de begeleidende huisarts bij het geven van feedback niet te streng wil beoordelen. De coassistent en de begeleidende huisarts zijn gedurende vier weken tijdens werktijden samen, wat het kritisch beoordelen van de student in de weg kan staan. Ook zouden de begeleidende huisartsen het negatief beoordelen van de student kunnen zien als een falen van zichzelf, omdat zij de taak hebben de student gedurende vier weken op te leiden. De gemiddelde beoordelingen van de examinatoren zijn dan ook lager. Verder beoordeelt de huisarts-examinator meer studenten, waardoor verschillen beter aangegeven kunnen worden.

Opvallend is dat bij meerdere items uit het observatieformulier 'examenpatiënt I' het berekende verschil tussen CIBA- en 
reguliere studenten sterk verschilt van hetzelfde item uit 'examenpatiënt II'. Zo geeft het item 'verwijzen en consulteren' bij 'examenpatiënt I' een positief verschil (.12) en bij 'examenpatiënt II' een negatief verschil (-.50). Een mogelijke oorzaak is de contextafhankelijkheid van deze manier van beoordelen. Ook de subjectiviteit van de beoordelaar speelt wellicht een rol.

De geluiden die vanuit de praktijk komen dat CIBA-studenten tijden coassistentschappen moeilijkheden ondervinden op het gebied van taal en communicatie worden met deze onderzoeksresultaten geobjectiveerd en deels worden ze ook bevestigd. Echter, gezien de eindresultaten lijkt van een groot probleem geen sprake te zijn. Verder onderzoek zal uitgevoerd moeten worden onder een grotere groep studenten, zodat een multivariate analyse uitgevoerd kan worden. Ook kunnen dan extra variabelen zoals kennisniveau en land van herkomst meegenomen worden.

\section{Literatuur}

1. Haalboom JRE, Herfs PGP. De inpassing van buitenlandse artsen in het Nederlands medisch curriculum. Het Utrechtse model. Med Contact 1998;44:1415-7.

2. Peeters O, Jongepier P, Nedermeijer J. Studieproblemen van buitenlandse studenten in het Nederlandse hoger onderwijs. Onderzoek van Onderwijs 1989;4:53-5.

3. Admiraal W, Boogaard M. In- en doorstroom van allochtone en buitenlandse studenten. Een analyse van inschrijfgegevens van de universiteiten van Eindhoven, Rotterdam, Utrecht en Wageningen. Utrecht: IVLOS, Universiteit Utrecht; 1994.

\section{De auteurs:}

Mw. drs. E.A. van Hell, onderwijskundige en onderzoeksmedewerker, Centrum Innovatie en Onderzoek Medisch Onderwijs, Universitair Medisch Centrum Groningen.

Dr. J. Greidanus, huisarts en onderwijscoördinator, afdeling Huisartsgeneeskunde, Universitair Medisch Centrum Groningen.

Dr. F. Beltman, huisarts en onderwijscoördinator, afdeling Huisartsgeneeskunde, Universitair Medisch Centrum Groningen.

Mw. dr. J. Cohen-Schotanus, hoofd Centrum Innovatie en Onderzoek Medisch Onderwijs, Universitair Medisch Centrum Groningen.

\section{Correspondentieadres:}

Mw. drs. E.A. van Hell, Centrum Innovatie en Onderzoek Medisch Onderwijs, Universitair Medisch Centrum Groningen, A. Deusinglaan 1, 9713 AV Groningen, tel.: 050-3637349, fax: 050-3633865, e.a.van.hell@med. umcg.nl.

\section{Summary}

Introduction: CIBA students are doctors with international qualifications that are not acceptable in the Netherlands. These students are required to follow parts of the undergraduate medical curriculum. Supervisors of CIBA students on clinical attachments report that CIBA students have problems with language and communication. However, so far any evidence has been anecdotal. We investigated whether CIBA students' performance differed from that of regular students and if so, in which areas these differences were most marked with the aim of objectifying supervisors' subjective observations.

Method: We analysed the results of the year 6 general practice rotation of 24 CIBA students and 24 regular students at University Medical Center Groningen. Students' results are based on five appraisal forms consisting of items about different aspects of general practitioners' work. The mean item scores of the CIBA students and the regular students were calculated for each appraisal form. Wilcoxon signed-ranks test was used for the analysis

Results: CIBA students generally scored lower than the regular students. The difference was significant for two of the forms (overall appraisal and examination patient I). The difference between the two groups was strongest for the items 'patient encounter', 'doctor-patient relationship' and patient management plan/skills.

Conclusion: Overall performance on the general practice rotation was slightly lower for the CIBA students compared with the regular students. The differences were most marked for items relating to doctor patient communication and interpersonal skills. The small study group and the possibility of effects of other factors warrant caution in interpreting the findings. (Hell EA van, Greidanus J, Beltman F, Cohen-Schotanus J. An analysis of foreign doctors' performance in the general practice rotation. Dutch Journal of Medical Education 2006;25(1):22-28.) 